\title{
Design of a Renewable hybrid photovoltaic- Electrolyze-PEM/Fuel Cell System using Hydrogen Gas
}

\author{
Bassam Zafar*ł \\ *Information Systems Department, Faculty of Computing \& Information Technology, King Abdulaziz University, Jeddah, \\ Saudi Arabia \\ (bzafar@kau.edu.sa)
}

"Corresponding Author, Bassam Zafar, King Abdulaziz University, 21589, Tel: +966 012640000,

\begin{abstract}
Home Automation (or Smart Home) is a residential platform that connects different network devices to meet needs using Internet, computer, communication and control technologies. Equipped with different sensors; home automation devices have become a potential area that attracts worldwide attention and interest in the development of Internet objects. It plays an important role in adding semiconductors to sensor data to better understand environments around it. Researchers are trying to build semantic models to meet their own needs, resulting in limited reuse opportunities between various platforms and home applications. To do this, paper aims to provide a new ontology that follows publicly recognized standards for semantizing sensor data in home automation, including modeling sensors, context and semantic activity. In this vein, we proposed a precise simulation model combining solar energy with an energy recovery (fuel cell). A long-term energy storage component includes a water electrolyzer that is considered as a primary storage component and an Ultra-Capacitor storage component used as a short-term energy storage component. A precise scheme approach for energy management unit is developed and discussed according to excess and deficit modes in order to achieve the correct system operation. The design being proposed is simulated using Matlab / Simulink environment to demonstrate the reliability and effectiveness of the control strategy being applied. Indeed, the proposed strategy aims to control system operation by referring to an experimental data profile extracted in a typical weekly working period mode from the Tunisian meteorological database with expected conditions.
\end{abstract}

Keywords Smart Home; Sensor Network; Solar energy; Fuel Cell ; Ultra-Capacitor; Hydrogen; Energy Management Unit; Simulation

\section{Introduction}

The world market prices for natural resources are growing annually. The human beings consume large amounts of natural resources such as oil, coal and natural gas, leading to a sharp decline in availability and accessibility. This massive consumption, by contrast, leads to severe pollution of the environment. It also causes the greenhouse effect [1][2]. In terms of conventional power production based on non-renewable resources, particularly fossil fuel, renewable energy sources have proven to be efficient alternatives. Solar energy is one of the most successful generations of renewable energy [3]. The solar energy source is widely used, because the nature of the source is easy, clean and abundant. It has now developed its technology well.
However, due to its fluctuating nature, a solar energy component (SEC) can be integrated with other alternative power sources and/or storage systems such as electrolyte, hydrogen storage tank, Fuel Cell component and Ultra condenser bank to overcome the intermittent solar system problem. Compared to commonly used battery storage, electrolytic hydrogen (H2) is well suited for seasonal storage applications as its inherent high-energy leakage from the storage tank is insignificant and easy to install anywhere [4][5]. Furthermore, the generator of fuel cells, especially the PEMFC, is a good option to integrate with the SEC power as many good features such as high efficiency, fast response, modular production and fuel flexibility [7] characterize it. The combination of Fuel cell component with the UltraCapacitor component is an attractive choice due to their high 
efficiency, fast load-response, flexibility and modular structure for the use with other alternative sources such as PV systems or wind turbines [8].

For example, the authors in [9] proposed three terms of use as battery and fuel cell of a solar-based hybrid system with different storage media. Their study includes a development of a management strategy that addresses the various operating conditions, including a thorough study of system efficiency and operating costs. However, Reference [10]'s studied work focuses on integrating photovoltaic fuel cell and ultra-capacitor systems for sustained generation of electricity. It provides a description of each component of the system followed by its modeling. The work also includes an evaluation of an adopted system management strategy. The authors in [11] presented an original control algorithm for a hybrid energy system with a renewable energy source integrating a fuel cell for a polymer electrolyte membrane and a photovoltaic array with a super-ultra-capacitor module. They studied the system's dynamic response followed by a control strategy. Therefore, their application can be dedicated to hybrid electric vehicles. In addition, a study of the various hybrid systems including fuel cell systems was conducted in the work presented in [12]. A system behavior study was then presented with a photovoltaic hybrid fuel cell generator integrating the battery as a secondary storage medium. Also included in the work was an appropriate power conditioning unit used to control system operation.

The rest of this paper is arranged as follows: Section 2 deals with the design of the Configuration of the integrated renewable energy; Section 3outlines the proposed energy management approach; Section 4 deals with the analysis of the simulation results and concluding remarks are discussed in Section 5.

\section{Configuration of the integrated renewable energy}

In this paper, as shown in Figure 1 the application of smart home appliances, renewable energy $(\mathrm{RnE})$, energy storage system, smart meter and smart home network was considered. Res such as photovoltaic cells (PV) can generate cached power in the storage system for later use. This section assesses the renewed system. The design models are the solar energy system, the Ultra-capacitor (UCap: storing system), and the fuel cell (for example an energy reservation system (ERS)). The Smart Energy Management Module (SEMM) has been developed based on a specific Actor-Sensor control unit. The proposed design was tested and simulated with the Matlab/Simulink environment in order to demonstrate system performance. Its own representative Actor provided each system. To gather information with other actors and the
Energy Management Unit, each representative is deployed. The Wireless Sensor Network (WSN) proposed intelligent home design to connect Actor devices, properly manage the operation of domestic appliances and optimize power consumption.

Solar energy is the energy generated by the photovoltaic module located on the roof of the house. The PV - produced current expression is depicted as [18].

$$
I_{G E N}=I_{p h}-I_{s} e^{\left(\frac{N_{S} \cdot V_{P V}+N_{P} \cdot I_{P V} \cdot R_{s}}{V_{T}}\right)}-\frac{N_{S} \cdot V_{P V}+N_{P} \cdot I_{P V} \cdot R_{s}}{R_{s h}}
$$

Total installed device consumption determines power consumption. It can be used for lighting, heating, entertainment. Electrolyzer is equipment that produces hydrogen by decomposing a water molecule into $\mathrm{H}_{2}$ and $\mathrm{O}_{2}$ gas, in the presence of an excess power current (Eq.2).

$$
\left\{\begin{array}{l}
V_{W E L}=\sum_{j}^{t} V_{j}=E_{r e v}+V_{a c t}+V_{c o n}+V_{o h m} \\
I_{E S C}=Y\left(V_{p v}\right)=\eta_{m} \frac{N_{s} V_{T}}{V_{w E L}} \cdot V_{p v} \\
Q_{\left(H_{2}\right)}^{P}=h\left(\eta_{F_{e l}}, I_{w E L}\right)=\frac{N_{c}}{2 F} I_{w E L} * \eta_{F_{e l}}
\end{array}\right.
$$

The generated hydrogen flow is calculated in accordance with the Faraday law [19]. $\mathrm{H}_{2}$ storage is a device for storing the produced hydrogen flux. The process of high-pressure storage follows the Eq. 4 [20] law. Supercapacitor equipment is an electrical device capable of performing through its discharge the energy recovery process (Eq.5). The Supercapacitor is regulated by its charging status to ensure its protection from deep discharge as described in the following expression [21]:

$$
\begin{gathered}
Q_{P}=\frac{\eta_{E L_{F}} \cdot N_{E L} \cdot I_{E L}}{2 \cdot F} \\
S O C_{H 2}=\frac{Q^{S}}{Q_{\max }^{S}} \\
\left\{\begin{array}{l}
U_{U S C}=R_{U S C} \cdot I_{U S C} \cdot \frac{1}{C} \int_{0}^{t}\left(I_{U S C}-I_{U S C}^{D H}\right) \cdot d t+U_{U S C}(O) \\
S O C_{U S C}=\frac{E_{\max }-E_{\min }}{E_{\max }}=\frac{1}{1-D_{\max }^{2}}\left(\frac{V_{U S C}^{2}}{V_{U S C_{-} \max }^{2}}-D_{\max }^{2}\right)
\end{array}\right.
\end{gathered}
$$




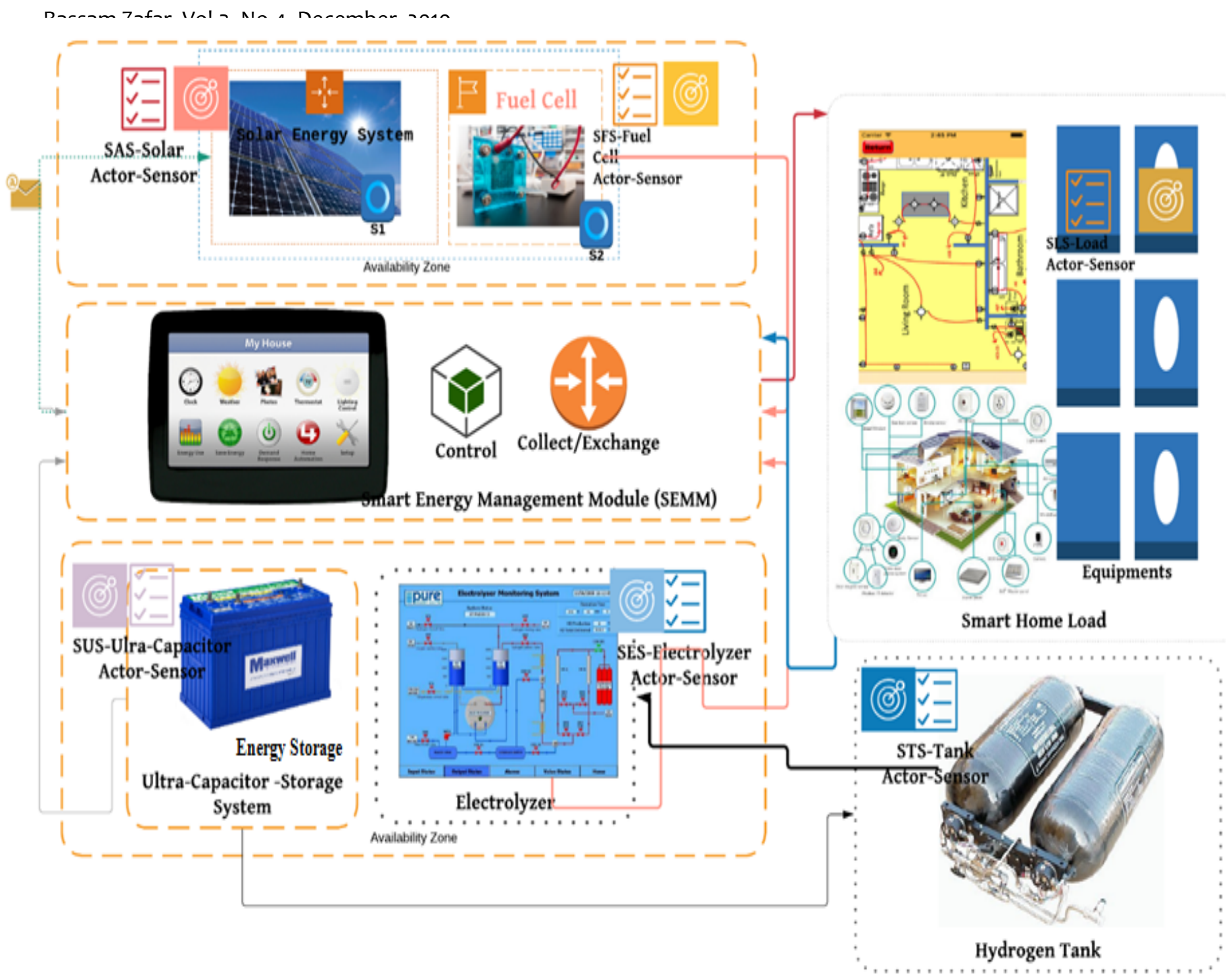

Fig. 1. Design System: Smart Home Dynamic model of Renewable Energy (RnE)

\section{Smart Energy Management Analysis}

Smart Energy Management (SEMM) is a system of different rules for monitoring independent system generation performance, control and improvement. In our case, the Actor Sensor system has been integrated into the proposed SEMM. Indeed, SEMM can offer platforms to create optimum agent interaction using artificial intelligence and mathematical tools. Furthermore, each Sensor can detect and act on its environment. The RNE Smart home diagram is shown in Figure 3. The proposed design is assessed on the energy demand for a specific Smart home load. This is why the SEMM is proposed to ensure cooperation among the various components of the system according to the value of the control current that identifies the system status. The control current is defined as the difference between the solar power supply current and the demand for smart home energy ( $\left.\mathrm{I}_{\text {Load }}\right)\left(\mathrm{I}_{\mathrm{CTR}}=\mathrm{I}_{\mathrm{SES}}-\mathrm{I}_{\text {Load }}\right)$. Therefore, the system can supply excess energy (when $\mathrm{I}_{\mathrm{CTR}}>0$ ). It is necessary to control and store the delivered excess power. The system reduces the deficit in the opposite case (when $\mathrm{I}_{\mathrm{CTR}}<0$ ). As a result, the excess current ( $\left.\mathrm{I}_{\mathrm{EX}}\right)$ and the current deficit $\left(\mathrm{I}_{\mathrm{DEF}}\right)$ are used as input parameters used to select which system elements are either on or off. Table 1 below shows the states of renewable smart home energy. The Sensor Actors system was modeled using Agent/UML the language. This language was chosen to evaluate, explain the sensor cooperation. The Figure 2 gives the Sequence Diagram of the Renewable Smart home. To manage and test system performance, the electrical load demand was chosen. Indeed, the Smart home load is regarded as the reference power for optimizing the components and achieving the desired performance. The proposed system was processed using a meteorological experimental data profile extracted from Sousse-Tunisia database. Indeed, in order to select the appropriate mode (excess/deficit), the proposed algorithm deals with supervising the distribution of flow energy (Figure $2 \mathrm{a}, 3 \mathrm{~b}$ ). 


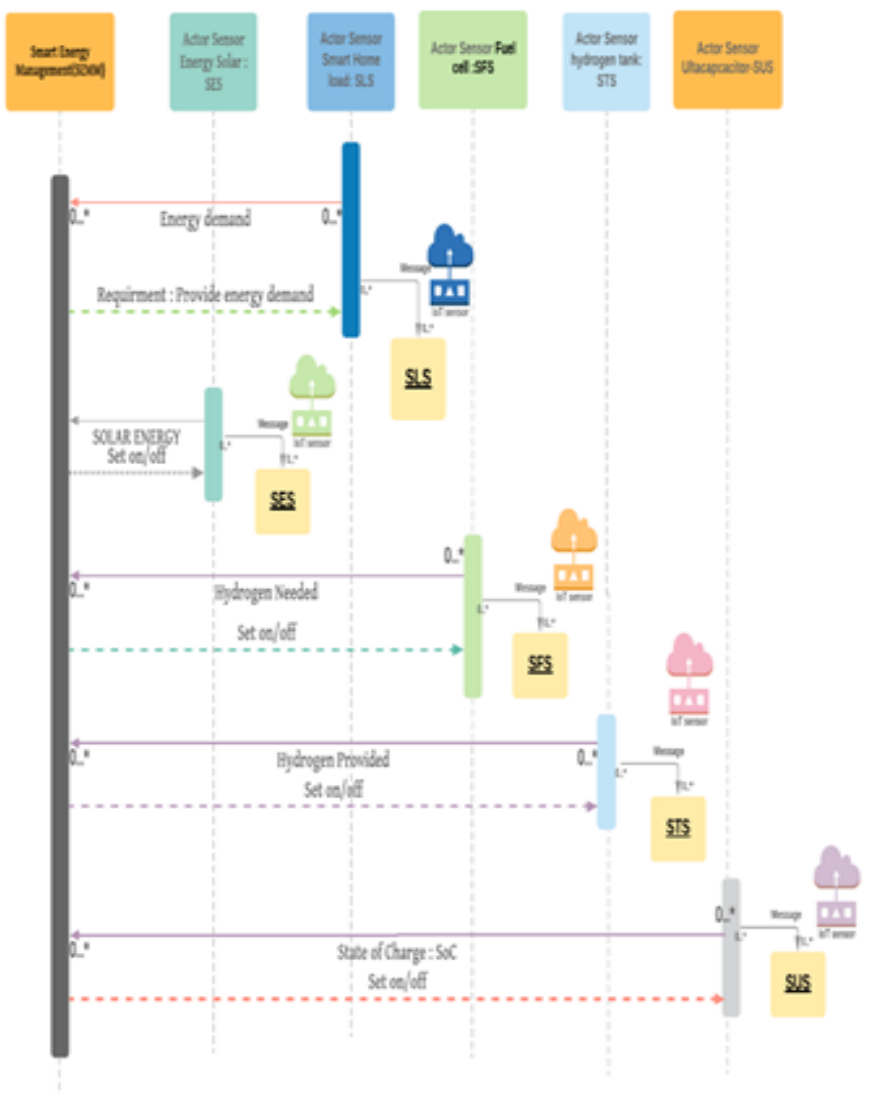

(a)

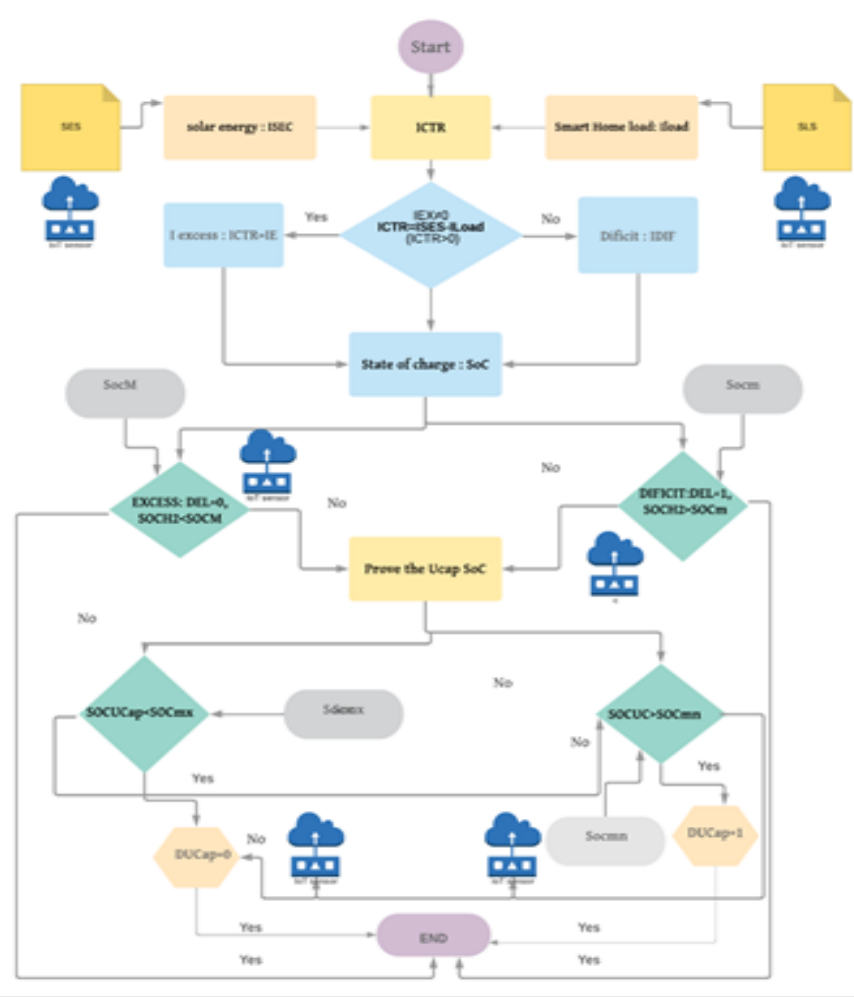

(b)

Fig. 2. Descriptive Scheme of the Energy Management Unit:

(a) System Control; (b) System Behavior

\section{Finding and Discussion}

In this section, we discuss the obtained results by simulating the renewable smart home block diagram using Matlab / Simulink to demonstrate the effectiveness of the proposed management strategy. An experimental Tunisian profiles describing home energy consumption and production was introduced and exploited in this vein. These input parameters are actually used to bring the system operation closer to reality and improve overall performance. Figure 3 shows the power balance between production and consumption during three consecutive days ( $72 \mathrm{~h})$.

The solar energy system is used as a primary source for energy demand satisfaction on the Smart home system. However, this feeding source decline of its inability to feed continuously the needs. In order to withstand any fluctuations, the system supports a behavior change based on decisions taken by the energy management unit. The EMU refers to a current (ICTR) that controls the process nature to be performed (energy storage/energy recovery) (see Figure 4). As seen, the system is located under excess and deficit periods. The power excess is controlled throw the current IEX to choose the appropriate storage mean during process operation. Whereas, the lack periods is managed by the current IDEF to compensate the deficit via the proper recovery element (see Figure 5).

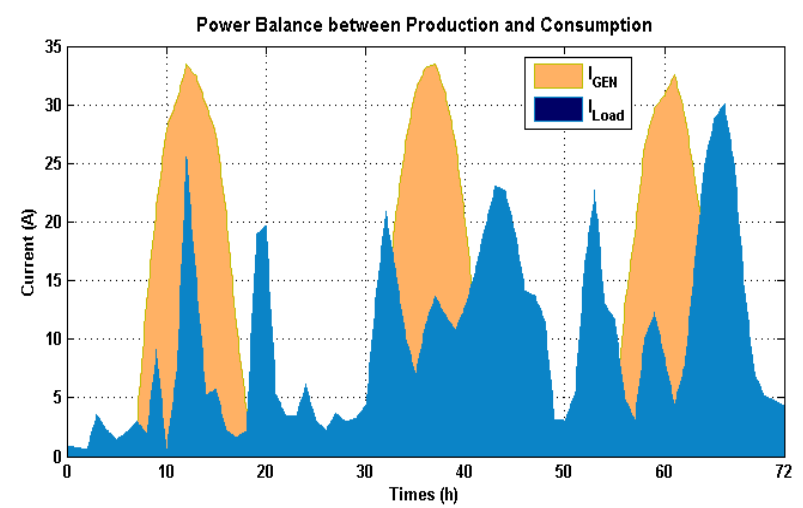

Fig. 3. Energy consumption and production profiles 


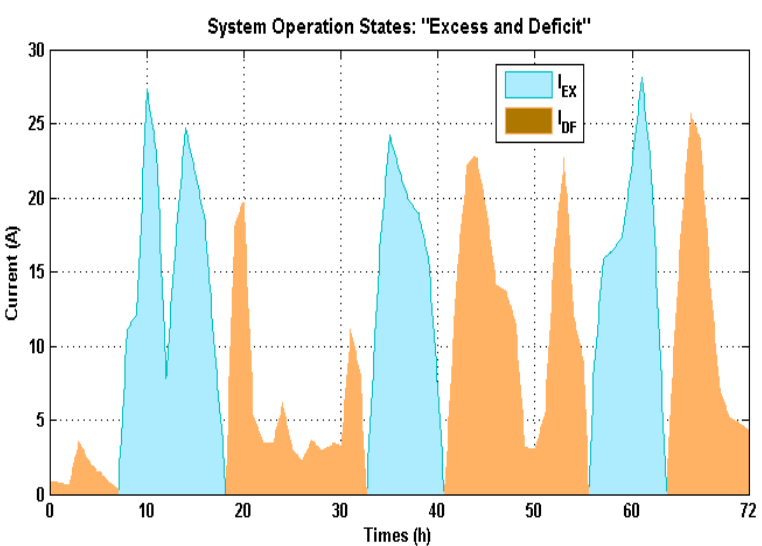

Fig. 5. Excess and deficit operation periods

During excess periods, the EMU resorts to hydrogen production component (Electrolyzer) to store the exceeded power. Indeed, when the nominal operation current is achieved IEX $=\mathrm{IN}$, the system launches the $\mathrm{H} 2$ storage process instead of ultracapacitor charging (see Figure 6). However, during deficit periods, the EMU checks the state component and launches the appropriate recovery component (Fuel Cell or ultracapacitor) that will effectively compensate the energy lack. Hence, the hydrogen recovery process ( $\mathrm{H} 2$ gas consumption) is highlighted when the operation nominal current is reached $(\mathrm{IDEF}=\mathrm{IN})$. Otherwise, ultracapacitor discharging process is triggered to maintain the load feed. So, the evolution of $\mathrm{H} 2$ consumption versus $\mathrm{FC}$ activation is illustrated in figure 7 .

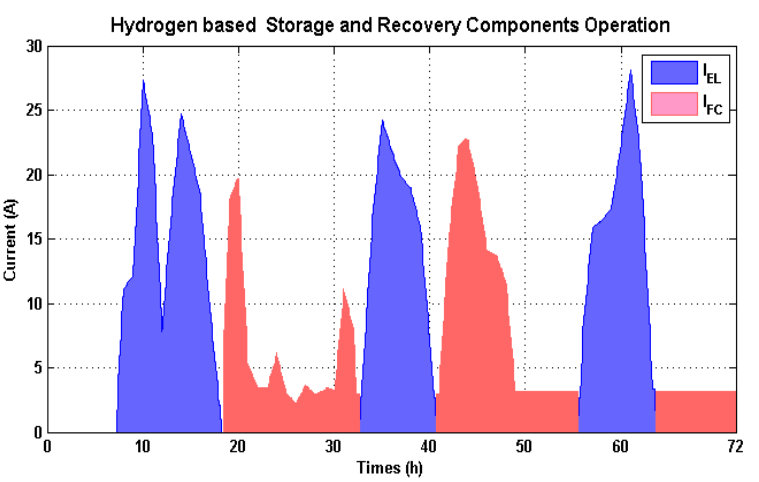

Fig. 7. Hydrogen production and consumption processes

The ultracapacitor component (UC) is located under two different states during its operation:

- Charging mode: "STORAGE PROCESS".

- Discharging mode: "RECOVERY PROCESS".

The evolution of UC current during the system running is depicted in Figure 8. In fact, during storage process, the UC is operated either when the nominal current value is achieved not IEX $<\mathrm{IN}$ or when the tank storage is full $(\mathrm{SOCH} 2=1)$. Although, when the system is located under deficit state, the $\mathrm{UC}$ is intervening either to regulate transient event as it processes a rapid response compared to $\mathrm{FC}$ or to compensate the lack in crucial $\mathrm{H} 2$ tank state (deep fuel consumption).

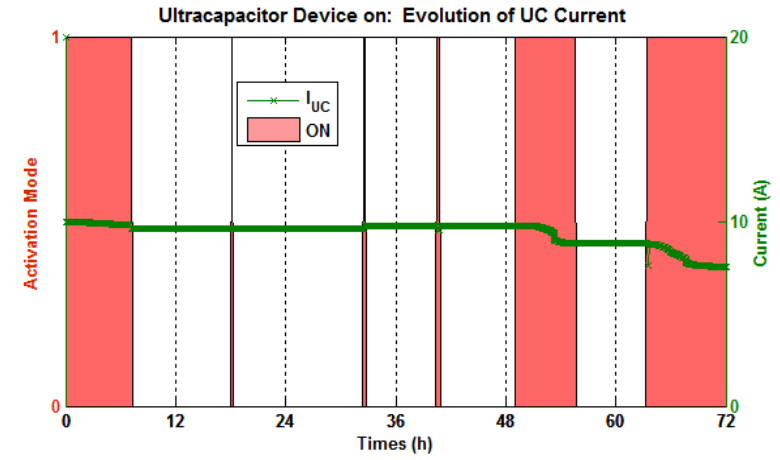

Fig. 8. Ultracapacitor operation process

Referring to operation state transitions, the EMU chooses the appropriate component that should complied with all the necessities. In this case, the system changes its behavior according to the tank state $\left(\mathrm{SOC}_{\mathrm{H} 2}\right)$ as well $\mathrm{UC}$ state (SOC $\mathrm{UC}_{\mathrm{UC}}$ ). From Figure 9, we can clearly notice that during the simulation test, the system is not located under any critical operation constraints. So, the stored hydrogen amount as the same for ultracapacitor device are stilling operated in normal conditions $\left(0<\mathrm{SOC}_{\mathrm{H} 2}<1 \& \& 0<\mathrm{SOC}_{\mathrm{UC}}<1\right)$.

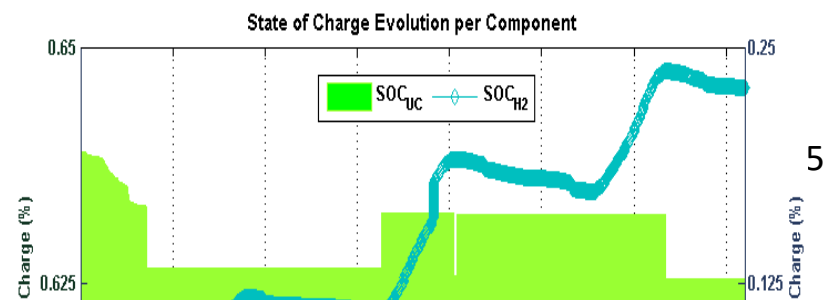




\section{Conclusion}

With Renewable Smart home scheme; this paper seeks to use hydrogen and Ultra-Capacitor long-term and short-term energy storage elements that are noted to have greater ability to regulate energy demand. In this sense, a Renewable smart home energy system was created, including solar energy, power regeneration, inventory of hydrogen and ultra-Capacitor, and an actor sensor system. The power recovery device was chosen as a secondary source to supply the necessary energy requirement. To fix the absence of energy during peak periods, a short-term energy storage device was included. Furthermore, an effective approach to energy management was suggested to regulate the necessary power (production/consumption). The simulation results showed the performance of the presented EMU as well as the flexibility and reliability of the proposed autonomous system by counteracting unwanted fluctuations to provide high-quality load power.

Future works on implementing and implementing a smart energy management system through an embedded system where the delay is a critical factor. This system is called a real-time system that minimizes high-energy costs and demand while optimizing energy design in relation to variation in the electrical measurement

\section{Nomenclature}

\begin{tabular}{|c|c|}
\hline $\mathrm{I}_{\mathrm{ph}}$ & : Photo-current of solar system \\
\hline $\mathrm{I}_{\mathrm{s}}$ & : Saturation Current of solar system \\
\hline $\mathrm{I}_{\mathrm{ESC}}$ & : Cell current of solar system \\
\hline $\mathrm{V}_{\mathrm{T}}$ & : Thermodynamic voltage \\
\hline $\mathrm{V}_{\mathrm{PV}}$ & : Voltage of the Photovoltaic \\
\hline $\mathrm{N}_{\mathrm{C}}$ & : Cell number \\
\hline $\mathrm{N}_{\mathrm{EL}}$ & : Cell number of Electrolyzer \\
\hline $\mathrm{I}_{\mathrm{EL}}$ & : Cell current of Electrolyzer \\
\hline$Q^{\mathrm{S}}$ & : Stored hydrogen amount \\
\hline $\mathrm{U}_{\text {USC }}$ & : Cell Voltage of the Ultracapacitor \\
\hline $\mathrm{R}_{\text {USC }}$ & : Coefficient of Ultracapacitor \\
\hline Iusc & : Cell current of Ultracapacitor \\
\hline $\mathrm{V}_{\text {USC }}$ & : Voltage of Ultracapacitor \\
\hline SOCusC & - State of Charge of Ultracapacitor \\
\hline
\end{tabular}

(C)

(mol)

(V)

(A)

(V)

\section{References}

[1] R. Zevenhoven, "Understanding greenhouse gases: mission being accomplished", Greenhouse Gases: Science and Technology, vol. 5, no. 6, pp. 695-696, 2015. Available: 10.1002/ghg.1580.

[2] H. Pathak, "Greenhouse Gas Emissions and Mitigation in Agriculture"Greenhouse Gases: Science and Technology, vol.5, no. 4, pp. 357-358, 2015. Available: 10.1002/ghg. 1528 .

[3] D. Hopwood, "Renewable Energy Focus, restyled!", Renewable Energy Focus, vol. 16, no. 4, p. 49, 2015. Available: 10.1016/j.ref.2015.09.015.

[4] T. Estermann, M. New borough and M. Sterner, "Powerto-gas systems for absorbing excess solar power in electricity distribution networks", International Journal of Hydrogen Energy, vol. 41, no. 32, pp. 13950-13959, 2016. Available: 10.1016/j.ijhydene.2016.05.278.

[5] G. Henri, N. Lu and C. Carrejo, "Mode-based energy storage control approach for residential photovoltaic systems", IET Smart Grid, vol. 2, no. 1, pp. 69-76, 2019. Available: 10.1049/iet-stg.2018.0159.

[6] F. Alvarez-Mendoza, C. Angeles-Camacho, P. Bacher and H. Madsen, "Semi-dispatchable generation with wind-photovoltaic-fuel cell hybrid system to mitigate frequency disturbance", Electric Power Systems Research, vol. 165, pp. 60-67, 2018. Available: 10.1016/j.epsr.2018.08.021.

[7] S. Shezan, "Optimization and assessment of an off-grid PV (Photovoltaic) -Diesel-Battery Hybrid Sustainable Energy System for Remote Residential Applications", Environmental Progress \& Sustainable Energy, 2019. Available: 10.1002/ep.13340.

[8] M. Hall and A. Goupee, "Validation of a hybrid modeling approach to floating wind turbine basin testing", Wind Energy, vol. 21, no. 6, pp. 391-408, 2018. Available: 10.1002/we.2168.

[9] H. Fathabadi, "Novel standalone hybrid solar/wind/fuel cell/battery power generation system", Energy, vol. 140, 
pp. 454-465, $2017 . \quad$ Available: 10.1016/j.energy.2017.08.098.

[10]H. Fathabadi, "Novel fuel cell/battery/supercapacitor hybrid power source for fuel cell hybrid electric vehicles", Energy, vol. 143, pp. 467-477, 2018. Available: 10.1016/j.energy.2017.10.107.

[11]P. Chaudhary and M. Rizwan, "Intelligent approachbased hybrid control algorithm for integration of solar photovoltaic system in smart grid environment", IET Smart Grid, 2019. Available: 10.1049/iet-stg.2019.0055.

[12]B. Ceran and K. Sroka, "Performance Analysis of a Hybrid Generation System of Wind Turbines, Photovoltaic Modules, and a Fuel Cell", Acta Energetica, no. 23, pp. 36-42, 2015. Available: 10.12736/issn.2300-3022.2015204.

[13]A. Cyril Jose and R. Malekian, "Smart Home Automation Security: A Literature Review", The Smart Computing Review, 2015. Available: 10.6029/smartcr.2015.04.004.

[14]B. GS, "Smart Technologies/Systems in Home Automation: A Review and Guideline to Implement for Smart Real Estate Projects", MOJ Civil Engineering, vol. 2, no. 1, 2017. Available: 10.15406/mojce.2017.02.00021.

[15] M. Miraoui, S. El-etriby, A. Abid and C. Tadj, "AgentBased Context-Aware Architecture for a Smart Living Room", International Journal of Smart Home, vol. 10, no. 5, pp. 39-54, 2016. Available: 10.14257/ijsh.2016.10.5.05.
[16]A. Cyril Jose and R. Malekian, "Smart Home Automation Security: A Literature Review", the Smart Computing Review, 2015. Available: 10.6029/smartcr.2015.04.004.

[17] Y. Pang and S. Jia, "Wireless Smart Home System Based On ZigBee", International Journal of Smart Home, vol. 10, no. 4, pp. 209-220, 2016. Available: 10.14257/ijsh.2016.10.4.19.

[18]N. Bizon, "Global Extremum Seeking Control of the power generated by a Photovoltaic Array under Partially Shaded Conditions", Energy Conversion and Management, vol. 109, pp. 71-85, 2016. Available: 10.1016/j.enconman.2015.11.046.

[19] Y. Devrim and K. Pehlivanoğlu, "Design of a hybrid photovoltaic-electrolyzer-PEM fuel cell system for developing solar model", physica status solidi (c), vol. 12, no. 9-11, pp. 1256-1261, 2015. Available: $10.1002 /$ pssc. 201510091 .

[20]F. Odeim, J. Roes and A. Heinzel, "Power Management Optimization of an Experimental Fuel Cell/Battery/Supercapacitor Hybrid System", Energies, vol. 8, no. 7, pp. 6302-6327, 2015. Available: 10.3390/en8076302.

[21] Y. Daus, I. Yudaev and G. Stepanchuk, "Reducing the Costs of Paying for Consumed Electric Energy by Utilizing Solar Energy", Applied Solar Energy, vol. 54, no. 2, pp. 139-143, 2018. Available: $10.3103 / \mathrm{s} 0003701 \times 18020056$. 